\title{
Anatomical investigation of the slender catshark Schroederichthys tenuis Springer, 1966, with notes on intrageneric relationships (Chondrichthyes: Carcharhiniformes: Scyliorhinidae)
}

\author{
ULISSES L. GOMES ${ }^{1}$, GERHARD O. PETERS ${ }^{2}$, MARCELO R. DE CARVALHO ${ }^{3} \&$ \\ OTTO B. F. GADIG ${ }^{4}$ \\ ${ }^{1}$ Universidade do Estado do Rio de Janeiro, Instituto de Biologia, Departamento de Zoologia, Rua São Fran- \\ cisco Xavier 524, CEP 20559-900, Rio de Janeiro, RJ, Brazil; grant from PROCIÊNCIA/UERJ/FAPERJ; \\ e-mail: ulisses@uerj.br \\ ${ }^{2}$ Fellowship from FAPERJ, proc. no. E-26/151.222/98 \\ ${ }^{3}$ Departamento de Biologia, Universidade de São Paulo, Av. Bandeirantes 3900, CEP 14040-901, Ribeirão \\ Preto, SP, Brazil; e-mail: mrcarvalho@ffclrp.usp.br \\ ${ }^{4}$ Universidade Estadual Paulista, Campus do Litoral Paulista, Unidade São Vicente - Praça Infante Dom \\ Henrique, s/n, CEP 11330-900, São Vicente, São Paulo, Brazil; e-mail: gadig@csv.unesp.br
}

\begin{abstract}
The slender catshark Schroedericthys tenuis Springer, 1966, originally described from two immature males, is redescribed on the basis of 12 specimens of both sexes, juveniles and adults (as well as the holotype and paratype). The supplementary specimens were collected off the northern coast of Brazil between Amapá and Pará states. Aspects of its external morphology, color pattern, dermal denticles, dentition, vertebral counts, and the cephalic, clasper and pectoral fin skeleton are described in detail and fully illustrated. These features are compared with those of congeneric species. Our observations support preliminary results of work in progress that $S$. maculatus Springer, 1966, S. tenuis and S. saurisqualus Soto, 2003 form a monophyletic group, mostly on the basis of neurocranial morphology, and that S. bivius (Smith, 1838) and S. chilensis (Guichenot, 1848) should be removed from Schroederichthys.
\end{abstract}

Key words: Schroedericthys tenuis, Scyliorhinidae, anatomical description, phylogenetic relationships, western South Atlantic Ocean

\section{Introduction}

Sharks of the genus Schroederichthys Springer, 1966 are small to medium-sized catsharks (Scyliorhinidae) restricted to temperate and tropical waters of South and Central America, occurring on the continental shelf and upper slope (Compagno, 1984, 1988). The genus 